\title{
Ritual in Online Communities: A Study of Post- Voting in MOOC Discussion Forums
}

\section{Emily Longstaff}

To cite this article: Emily Longstaff (2017): Ritual in Online Communities: A Study of PostVoting in MOOC Discussion Forums, International Journal of Human-Computer Interaction, DOI: 10.1080/10447318.2016.1277639

To link to this article: http://dx.doi.org/10.1080/10447318.2016.1277639

Accepted author version posted online: 06 Jan 2017.

Published online: 06 Jan 2017.

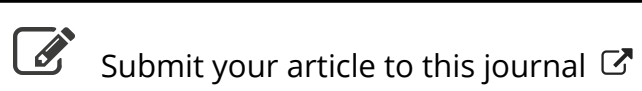

Џll Article views: 30

Q View related articles $\circlearrowright$

View Crossmark data $₫$ 


\title{
Ritual in Online Communities: A Study of Post-Voting in MOOC Discussion Forums
}

\author{
Emily Longstaff \\ School of Sociology, Australian National University, Acton, ACT, Australia
}

\begin{abstract}
When building a community, whether online or offline, rituals are key. They guide social interaction by expressing standards of behavior and social boundaries through patterned series of symbolic words and acts. With Massive Open Online Courses (MOOCs) as a case study, this article demonstrates how postvoting in online discussion forums-including those in education contexts-can both enforce and undermine the development of community precisely because of the ritual power such mechanisms assume, inclusive and exclusive. Anyone seeking to cultivate communities online through the use of discussion forums should be wary of this issue with regard to user interaction.
\end{abstract}

\section{Introduction}

By working to create and foster learning communities, designers of online education platforms aim to foster some degree of social networking and emotional attachment among users. This can help users combat feelings of alienation from studying alone on a computer rather than with a group in a physical classroom. Online education environments with a strong sense of community have also been associated with increased learner motivation and satisfaction, as well as reduced rates of attrition (Dawson, 2006; Tinto, 1993; Wilson, Ludwig-Hardman, Thornam, \& Dunlap, 2004). Moreover, there have been suggestions that the asynchronous nature of most online learning environments leads to more considered reflection on course materials and peer engagement than may be found in face-to-face settings (Bennett, Chan, \& Polaine, 2004; Guilar \& Loring, 2008). For all of these reasons, concerted effort to establish community sentiment in online education environments is therefore viewed as an essential part of retaining learners over time and imparting them with the best possible knowledge moving forward.

One relatively new online education environment is that of the Massive Open Online Course, better known as the "MOOC." This kind of largely free, video-based online course gained global popularity in 2012 with the emergence of three US-based MOOC providers-Coursera, edX, and Udacityeach professing, as part of their mission statement, a goal of "connecting" learners through their educational offerings (Coursera, 2014a; edX, 2014a, 2014b; Udacity, 2014a, 2014b). This priority is understood as the need to foster community sentiment among MOOC peers, to encourage users to support one another to persevere with current and future studies, and to sustain the pool of participants over time. The promotion of such a community spirit points to what has been marketed as the underlying driver to the very creation of MOOCs: inclusivity. The idea is that anyone and everyone who has access to the internet and a desire to learn is welcome to participate in MOOCs and become part of the MOOC community.

While much has been written about MOOCs in terms of attrition - which, according to Wilson et al. (2004), may be an indication of a poor sense of community among users-little emphasis has been placed on the notion of community specifically in relation to MOOCs. In bridging this gap, this article presents a study of the group dynamics of MOOC participants observed through their interaction in official discussion forums. This then shows how the development of community may be impacted by online behaviors, with particular attention paid to the role of ritual in establishing in-group/outgroup boundaries and reinforcing social norms.

\section{Communities Online}

Despite definitional peculiarities, traditional conceptions of community have generally centered on the notion of a sense of commonality or belonging to a group of people occupying a particular geographical place (Conrad, 2002; Fernback, 2007; Hillery, 1968). Over time, emphasis has shifted toward the notion of attachment instead of relative distance, that is, on the creation and maintenance of ties that exist in social rather than physical space (Fernback, 2007; Garton, Haythornthwaite, \& Wellman, 1997). From this perspective, community is an imagined entity or "a psychological construct," as Dawson (2006, p. 496) proposes. As such, nowadays a community is as real as its participants claim it to be.

Far from being dominated by staunch individualism, contemporary society is full of people fueled by a need to "belong," according to Guibernau (2013). This desire to belong - to interact with groups of like-minded people and feel some level of attachment in return-has been made especially evident by the proliferation of internet technologies and the ease at which 
communities can now be formed around the globe. With a few clicks of a button on a computer, smart phone or tablet device, people separated by vast geographic distance can connect with others who share similar interests or ideas and, in doing so, establish meaningful relationships through online social networks (Lee \& Lee, 2010). In this "boundless" and digital world, place-based definitions of community no longer suffice.

However, due to its symbolic nature, just what defines an online community varies alongside the phenomena under study (Toder-Alon, Brunel, \& Schneier Siegal, 2005). According to Fernback (2007, p. 66), "the meaning of community evolves as we devise new ways to employ it" and conceptions of community can be so all-encompassing that they may actually have little meaning at all:

Community is descriptive and prescriptive, local and global, spatially bound or boundaryless, public or private, organic or mechanical, intentional or accidental, purposive or aimless, oppressive or liberating, functional or dysfunctional. It can be a shared interest, shared kinship or shared space. It can be physical locality or collective interests or collective memory or crisis constituencies or marketing devices. (Fernback, 2007, p. 52)

Nevertheless, Fernback (2007) still sees value in studying the notion of online or "cyber" communities, regarding them as one of today's key "social relational structures" (p. 53). The crucial issue, she argues, is identifying what constitutes a specific online community and how it operates, rather than using a "broad brush" to categories all online arenas as one (Fernback, 2007, p. 66). To start with, one must first establish precisely what one means by the term "online communities." One definition, offered by Bagozzi and Dholakia (2002, p. 3), is of "mediated social spaces in the digital environment that allow groups to form and be sustained primarily through ongoing communication processes." $\mathrm{As} \mathrm{Xu}, \mathrm{Li}$, and Shao (2012, p. 347) put it, a community that exists entirely in the virtual world is "a type of online structure that enables internet users to communicate and collaborate." In other words, an online community is essentially a discursive entity, a mini "cyber-society" that emerges out of prolonged interaction, through text-based conversations, on specific sites or platforms hosted on the internet. Such online communities can be found in all sorts of settings, from online chat rooms and social networking sites to purpose-built online education environments (also referred to as online learning or e-learning environments). Primarily, it is the latter that is of particular interest to this study.

While online education is itself viewed as a means to overcome time and geographical constraints and thereby increase the accessibility of higher education, it is often criticized for the lack of social interaction that it offers to learners. This criticism stems from the fact that online education lacks the physical co-presence inherent to on-campus education. The chief concern is that, without physical co-presence, learners are denied opportunities for face-to-face interaction. This is an issue for many educationists because face-to-face interaction has come to be regarded as one of the most fundamental characteristics of a traditionally-defined "good learning" experience (Macfadyen, 2009, p. 93). It results not only in the creation of new knowledge but also in the nurturing of social skills and relationships. By actively working to create and foster community ties among participants, designers of online education platforms aim to assuage these concerns about the lack of physical co-presence. Certainly, as online education has become more prevalent over the years, researchers have sought to examine precisely how teachers and education designers can encourage learners to cultivate communities with their online peers, such as through the use of asynchronous discussion forums (see: deNoyelles, Zydney, \& Chen, 2014; Horchler, 2001; Joanne \& Tim, 2004; Palloff \& Pratt, 2005; Parr \& Ward, 2006; Phirangee, Demmans Epp, \& Hewitt, 2016; Shackelford \& Maxwell, 2012). In accordance with this line of inquiry, the study presented in this article specifically addresses the issue of how the user interface of online education discussion boards, or indeed any platform based around peer engagement, can impact community development. Specifically, it looks at the mechanisms of MOOC discussion forums that encourage ritualized behaviors and, in turn, the role that such behaviors play in establishing or impeding social bonds between MOOC users.

\section{Ritual in Online Communities}

Like community, there are multiple interpretations of precisely what constitutes ritualized behavior. Rook (1985, p. 252) defines ritual as "a type of expressive, symbolic activity constructed of multiple behaviors that occur in a fixed, episodic sequence and that tend to be repeated over time." For Tambiah (1979, p. 119), "ritual is a culturally constructed system of symbolic communication...constituted of patterned and ordered sequences of words and acts." Toder-Alon et al. (2005, p. 21) take a different tact, conceiving rituals as "social knowledge structures that are organized and stored in memory in the form of particular scripts", that is, "shared social schemas' that contain expected sequences of communicative practices to reach certain goals or to behave appropriately in certain settings." In combining these different views, this study defines ritual as highly symbolic and stylized patterns of behavior that work to express or maintain social order (Guibernau, 2013; Taylor \& Whittier, 1995; Wuthnow, 1987).

According to Durkheim (1961), expressive human behavior-that is, ritual-is socially, emotionally, and morally significant for separating the "sacred" in society from that of the "profane." Ritual, for Durkheim, is thus an important tool for establishing social unity and boundaries around accepted attitudes and behaviors (Rawls, 2004). Contrary to assertions that ritualized behaviors should be relegated solely to the realm of primitive cultures, as Hobsbawm (1959) proposes, they are useful for interpreting even the most mundane human occurrences. Indeed, Goffman (1967) puts forward the notion that ritual can actually be found at the core of everyday interactions, that all social encounters actually abide by a degree of "ritual organization" (p. 45) when it comes to the use of language, gesture, and space, and that all of these elements of interaction carry specific symbolic meaning (pp. 55-58). Precisely because of its fundamental role in guiding social interaction and standards of behavior, ritual impacts "the whole life of a community" (Connerton, 1989, p. 45) and may in fact be what helps "conjure a sense of community" in the first place (Magolda, 2000, p. 24).

In supporting the development of a community, ritual can both restore social equilibrium and exaggerate differences or 
disturbances (Bell, 2009; Toder-Alon et al., 2005; Turner, 1974). Likewise, ritual can be considered both the performance of established norms and relational boundaries as well as the creation of them:

Rituals...acknowledge and commemorate existing elements of identity, and they contribute to the construction of new forms, and new interpretations, of community and collective identity. They allow individuals to celebrate, maintain and reinforce existing bonds, and they are routinely employed to create new social and interpersonal bonds. (Macfadyen, 2009, p. 98)

In spite of Collins' (2004) claim that rituals require physical copresence of people's bodies in order to be successful, scholars have begun to see the nature and conception of ritual as changing alongside broader changes in society and the ways we communicate and interact with one another. Indeed, online communication practices make an excellent case study for ritual. Maloney (2013) and Milan (2015) both argue that online media actually renders the physical co-presence requirement of social interaction-and thus interaction ritual-simply a characteristic of some forms of social exchange, not a necessity for any exchange. This is because new media devices arguably make communicative intent much more explicit than what can be achieved in face-to-face interaction. Bodily gestures or indirect verbal cues-such as tone of voice-require a certain deal of interpretive work and cognitive processing during a physical interaction. Online exchanges, however, can be surmised succinctly by specific and deliberately selected images and colors, both of which provide a visual gauge for emotional meaning and tone. Online communicative intent can also be conveyed through written words, which, by nature of the medium of the internet, can be often reread and rewritten to help clarify the intended meaning of a message. The level of consideration of message and response varies according to whether or not the online interaction-and thus the interaction ritual-is synchronous (in real time) or asynchronous (staggered over time). In either circumstance, analysis of online ritual behavior is about identifying symbols and gestures that shape user interaction. More explicitly, it is about locating and decoding the shared understanding and repeated use of textual and visual symbolic devices that users employ in communication-the "common symbol system," as Boyd (2002) would describe it. The examination of online ritual behavior is also about understanding and explaining how such devices "promote community pride, sense of collectivity, and cohesiveness" and, in turn, cultivate an "us" and "them" divide (Toder-Alon et al., 2005, pp. 24-25).

One example of online interaction ritual that operates on the basis of a common symbol system is the use of the "like" button on the social networking site Facebook. This is what Sutcliffe, Gonzalez, Binder, and Nevarez (2011, p. 1052) term an example of a "direct social cue," one of an array of "explicit metaphors, icons, and other representations on the [Facebook] user interface that communicate socially relevant information." The act of "liking" a Facebook post is a repeated activity, done regularly by millions of users and with the same intended effect: Each user clicks on a specific digital symbol (the "like" button) to communicate a shared understanding of approval or alignment of a belief, action, or behavior as expressed by their friends or acquaintances. The "likes" of others also work to boost the visibility of certain posts in the user's newsfeeds, just as their "likes" will impact the newsfeeds of others. This process then imparts a certain degree of importance to a particular kind or source of content over others.

Similar to Facebook, MOOCs enable users to attribute value to the posts of others through symbolic gestures. The three main MOOC providers-Coursera, edX, and Udacityall have their own shorthand system for assigning positive or negative feedback to user posts, each intended to impose a hierarchy to discussion threads based on popularity. The most salient of these post-voting systems is Coursera's "up-anddown" voting system, in which users can assign a green upward-facing arrow to posts for which they wish to signify agreement or commendation, or a red downward-facing arrow for disagreement or condemnation. While all three providers have indicated that post-voting is a way for the millions of users participating in MOOCs to wade through masses of user-generated content, observation of post-voting as a kind of interaction ritual shows that it actually plays a much bigger role in establishing and undermining the development of community sentiment in MOOCs.

\section{Method}

The focus on discussion forums in this study relates directly their intended function in web design circles a means to generate and sustain online communities (Lin, 2010). In capturing and decoding rituals between MOOC users in official discussion forums, this study has employed "netography," an increasingly popular subfield of ethnography in which the community under study both exists and interacts in an online environment (Kozinets, 2002). As with any ethnographic study, the goal has been to observe online subjects in their natural setting and draw attention to aspects of behavior that may generally receive little attention (Jackson, 1983; Kawulich, 2005; Lareau, 2011). Essentially, the goal has been, as Hine (2009) proposes, to explore and describe the constitution of a particular culture. More specifically, this study has aimed to shed light on the dynamics of MOOC participation, the construction and maintenance of social solidarity among MOOC users, and any instances of governance or self-governance that impact individual behaviors in MOOC discussion forums.

The process of observing interaction in the discussion forums was done as part of a broader investigation into the attitudes, behaviors, and experiences of MOOC users, in which users were invited, via the forums, to complete an online survey about MOOCs. For the sake of simplicity, the MOOCs under study were the same for both the survey and observational aspects of the investigation. In all, there were 94 courses across Coursera (from 47 different course creators), 56 across edX (29 different creators), and 49 across Udacity (13 different creators). These courses comprised a variety of subjects-ranging from visual arts and social sciences to physical science and technology-run over the 120-day period in which the survey took place (between June and October 2014). Gaining access to the forums meant enrolling in each course individually and posting an invitation to partake in the online survey in the general discussion thread of each course (where such threads existed). After this isolated forum post had occurred, user interaction on the various threads comprising each course's 
discussion forum was then observed. During the observation process, considerable reflection went into understanding what participants were saying, what factors were shaping the nature of interaction, and whether there were any common themes across different courses. Importantly, identification of ritual was not an explicit objective of the empirical investigation into the interaction on the forums but rather a fortuitous discovery. Also, observation of the forums was done covertly so as to preserve the nature of interaction and not impede or influence discussions between MOOC users (Kellar, Hawkey, Inkpen, \& Watters, 2008; Schwartz \& Schwartz, 1955). Any acknowledgement of the observer's presence was thought likely to result in the natural discussion environment being "seriously comprised or even destroyed" (Elm, 2009, p. 72).

\subsection{Ethical Considerations}

In gaining project approval from the Australian National University's Human Research Ethics Committee, it was made clear that informed consent, while a fundamental principle for ethical research of human subjects, is not always possible or preferable with observation studies (Bowker \& Tuffin, 2004; Eysenbach \& Till, 2001). The issue of feasibility is particularly true in the case of online research, where the pool of subjects under examination continues to fluctuate-as is the case of MOOCs, which have persistent fluctuations in course enrolments and user engagement (Elm, 2009; Waskul \& Douglass, 1996).

Despite these research and logistical concerns, and the premise that observational research often requires the observer to remain hidden from his/her research subjects so as not to disrupt their natural behavior-which is the very issue under study - some criticism remains with regard to the ethics of covert observation of online interaction (Bowker \& Tuffin, 2004; Huff \& Rosenberg, 1989; Kawulich, 2005; Kozinets, 2002). The key issue is whether or not the online environments under study are considered "public" or "private" spaces, which, as Hudson and Bruckman (2004) and Elm (2009) note, is not so easily determined. What Waskul and Douglass (1996, p. 131) argue is that the online world is both "privately public" and "publicly private"; there is no finite distinction. Because of this, certain issues need to be addressed to determine whether or not netography is an ethically sound method for research. In addressing the ethical permissibility of analyzing interaction in online forums specifically, the key issue for researchers to consider is how participants of these forums perceive their specific space in the cyber world and the nature of the interaction within that space (Elm, 2009; Waskul \& Douglass, 1996).

In accordance with this idea, researchers can assess the levels of expected privacy in online forums using three criteria: (1) the scale of the forum-those that have large numbers of participants are deemed to have lower the privacy than those with few participants; (2) how accessible the forum isthose requiring users to register before accessing or adding content are regarded as more private than openly accessible ones; and (3) the focus of the forum-those addressing sensitive issues are said to imply higher levels of perceived privacy than those targeting benign topics (Eysenbach \& Till, 2001; Hudson \& Bruckman, 2004; Waskul \& Douglass, 1996). Based on these criteria, observation of MOOC forums was deemed ethically permissible. Firstly, the privacy policies and terms of use/service of the MOOC providers at the time of the empirical investigation described MOOC forums as public spaces. ${ }^{1}$ Secondly, the MOOCs for which forums were observed comprised large numbers of users, often in the tens to thousands. As such, it is fair to assume that what was being observed in the process of the investigation was unlikely to be perceived by the research subjects as constituting an intimate social interaction. Thirdly, although registration was required to gain access to the forums, enrolment in MOOCs was, and still is, essentially open to anyone with an e-mail address. Lastly, the MOOCs studied have not covered topics anywhere near as sensitive as those in other studies where covert netography has already been used, like Brotsky and Giles' (2007) examination of an online pro-anorexia community.

Granted, even with scale, accessibility and sensitivity considered, participants in the forums under study may not have foreseen their comments being used for research purposes. This, Elm (2009) suggests, is another important ethical issue for internet researchers to consider. Also worth noting is Orgad's (2009) point that, as in any online research environment involving user behaviors and interaction, only the "visible" could be studied. These issues of active participation and research output aside, the main ethical concern for this study was simply that participants' identities and views were respected in the write up of results and that research was conducted with good "netiquette" in mind (Smith, 2006).

\section{Results}

One of the most prominent issues around user interaction within the MOOC forums, and the focus of this study, was postvoting. As already discussed, Coursera's post-voting systemwith its green upward-facing arrows for positive scores and red downward-facing arrows for negative scores-was shown to be the most explicit representation of a user-directed system of community values. It clearly demonstrated an embedded mechanism for users to indicate alignment with certain beliefs or standards (positive green scores) or disassociate themselves from those deemed unsuitable or disruptive (negative red scores). Conversely, edX had a "star" system for drawing attention to posts which users thought were particularly relevant or interesting, whereas Udacity had a simple number count. What made Coursera's system stand out-and make it the chief subject of this study-was its use of colors and arrows. The significance and ease at which votes were cast in its discussion threads were also important and likely a reflection of the structure of the forums themselves, which were much more ordered and easily navigate than those on Udacity or edX.

Perhaps the most striking observed example of the power of post-voting to impact the nature of interaction was in the Coursera course, A Brief History of Humankind. One thread in the discussion forum of this course that garnered a considerable number of votes revolved around the post of a user who condemned the occupation and attacks on the Gaza Strip by Israeli forces. Because of a perception that the course provider (the Hebrew University of Jerusalem) supported these attacks, this user said that she wanted to dissociate 
herself from the course by withdrawing her enrolment. In addressing an ongoing issue that is never far from controversy, the original poster's comments, perhaps unsurprisingly, stirred up strong debate among others in the course. One of the original poster's most divisive and poorly received posts was this one, which attracted a score of minus 104:

Hi all. I'd enrolled in this course with much enthusiasm, as it had been recommended in one of my previous courses and I awaited its start date. However, since I support the BDS movement, especially after the horrific assault on Gaza by Israeli Occupation Forces in July/August this year, I will be unenrolling from this Hebrew University course. The Hebrew University, from what I have learnt, is supportive of Operation Protective Edge and solicited donations for its students serving in this Operation, i.e. soldiers killing civilians indiscriminately and destroying Gaza, making it even less habitable than it previously was....I hope I am not offending my classmates in this course, nor the instructor, but I hope the significance of peaceful protest such as this, will make a difference over time.

Some users tried to change the original poster's mind about un-enrolling, telling her that the course was aimed at promoting knowledge and dialogue, and therefore, by ceasing her involvement in the course, she would only be hurting herself. Others welcomed her decision to leave. The heated debate that ensued between the original poster's supporters and opponents was so strong that course staff had to step in and moderate the discussion. In the process, hundreds of votesboth positive and negative-were cast on either side of the debate. As one other course participant commented on the situation: "Sapiens, look at what we have done! Taken a peaceful enclave and turned it into a war zone. At least we are consistent."

Besides expressing a need for mutually respectful interaction, one of the major issues recognized by MOOC users in this course, and in others, was the role that post-voting had to play in how a user came to feel their comments were being perceived by others and, moreover, how users started to perceive MOOCs more generally. Take the following quote from a fellow participant in A Brief History of Human kind:

-11 for pointing out that Reagan's White House considered Mandela "one of the more notorious terrorists" in the 80s[?] I thought this up-vote, down-vote system was to highlight useful content, and that this wasn't Facebook with ancillary academic content.

Despite criticizing the use of post-voting in course forums and the damaging impact it could have on one's perceptions of others-as right or wrong, friend or foe-this user received three positive votes for this particular comment. That separate instances of this user's comments-each expressing the same sentiment-were attributed with both negative and positive scores show a simultaneous disregard for the message he put forward and a reinforcement of it. The simple accumulation of votes for user posts illustrates how the MOOC user interface-across Coursera, edX, and Udacity, but here specifically in reference to the former-has enabled superficial approval or dismissal of particular comments without the need for constructed arguments in support of such gestures. For some, including the user quoted above, this was regarded as the kind of behavior found on social networking sites; behavior that MOOCs-marketed as high-quality higher education courses-would surely be distanced from. The sentiment expressed by those opposed to post-voting was essentially that, as proposed university-level equivalents, MOOCs should necessitate more effort and considered debate in discussion forums than simple "point-scoring."

Nonetheless, because of the ease of clicking an up or down arrow instead of taking time to formulate a considered written response, the numbers of votes attributed to MOOC user posts-and thus supporters or opponents to particular posts -have been able to mount quickly. As a consequence, postvoting has been shown to have considerable bearing on MOOC user experience, especially when certain users have come to feel that whatever they say would be targeted by others. As the following quote from Coursera's Introduction to Philosophy course demonstrates, post-voting has become detrimental to the very spirit of inclusivity on which MOOCs have been founded:

\begin{abstract}
It's small when one comment gets one down-vote. But overall, this issue is not small. If you haven't seen a thread where people pile onto a minority view (no matter how respectfully written) or a person followed around with every comment down-voted, you may not realize. It can be used to discourage speaking out, to silence opinions, and to bully. These are not small things in a supposedly educational environment encouraging participation and dialogue ... I've seen threads with a hundred down-votes (and a hugely vibrant discussion underneath precisely because the topic was something people really did want to talk about, even if they disagreed with the [original poster]). I've also seen (and been the target of) someone downvoting every comment, no matter the subject or content, of a particular person.
\end{abstract}

This sentiment was shared by another participant in Coursera's Paradoxes of War course:

\begin{abstract}
Some people are too quick to judge the intent of other people's words negatively, without any knowledge of the person. Sometimes one should take the words at face value without judging them to be sarcastic or unkind....Speaking of unkindness, piling [on] down arrows is unkind; this is done too often. It is unkind because it is done anonymously and without comment or questioning the person's intent. If you don't like what someone says, why not have the courage of your conviction and identify yourself and ask what the person meant? Piling [on] down arrows can have the unhealthy effect of shutting a person up; who needs the aggravation? So: ask what is meant before you judge intent. Don't down arrow without stating why. Sometimes a cigar is just a cigar; sometimes the plain meaning is the meaning.
\end{abstract}

Importantly, though forming the bulk of analysis presented in this article thus far, such sentiments were not limited to Coursera users. Similar expressions of disillusionment with post-voting were expressed by participants in Udacity forums, with suggestions that any users who adopted a consistently poor voting strategy were akin to "tyrants" bent on taking up "torches and pitchforks" to all who contradicted the views of their "mob."

It may seem predictable that MOOCs would inevitably attract negative votes since such large and diverse numbers of users would inevitably disagree. In some cases, exchanges of negative votes appeared to be "tit-for-tat" dialogue between users intent on criticizing each other, like this correspondence 
between participants in Coursera's The Addicted Brain, for which the first user post (labeled here as Respondent A) received two negative votes, while the second user post (labeled as Respondent B) received one negative vote:

Respondent A: I won't be responding again. I came here to learn and share ideas, not get into a pissing match with someone begrudging a system [that] really seems to work for a lot of people. It's just not my groove buddy.

Respondent B: Nice effort ...but hiding your weak argument behind 50 cent words (some of which are in the wrong tense) does nothing to mask your ignorance, arrogance, or convoluted logic...you are simply a blowhard who is an authority on practically everything in his own mind. I'm glad that continuing this discussion isn't your "groove," but I'm afraid you've already exposed yourself for what you are.

Instances where criticisms were directed at course content or instructors, however, indicated more of a concerted "rallying of the troops," so to speak; a show of solidarity by the pro-MOOC community against any disrespecting - and seemingly minority -voices. There were repeated instances were pro-MOOC users appeared to take such criticisms very personally, resulting in backlash against the apparent "anti-MOOC" users. One such user who was ridiculed for their critical course feedback was the person who posted this remark in the discussion forum of Coursera's Introduction to Philosophy course:

I find the lectures visually very boring and quite irritating. Most of the lecture is taken up with someone talking to the camera. There are hardly any different pictures or angles to relieve the visual boredom. Then the choice of where the shot is cut off is irritating because I can't help focusing on the hands waving about, which is very irritating. I end up just listening to the lectures, and trying not to watch if I can possibly help it. Surely it wouldn't take too much effort to make the lectures visually more interesting and less irritating. I don't expect them to be works of art, but they are comparable with the Open University programs of the 1970s.

Not long after being posted, this comment was met with six negative votes and a torrent of ridicule from other users. One user even advised the original poster that, as someone taking what has been deemed equivalent to a university-level course, they should be more focused on informational content than aesthetics and that "if one is looking to be visually entertained" then perhaps they should "try Disneyland." In another reply, one user suggested the original poster should show a greater degree of gratitude toward the course and whatever it had to offer. This is because, despite the high cost involved in creating MOOCs, for the users, the end cost has been made "free" in the vast majority of cases, at least as far as tuition is concerned:

\footnotetext{
The typical Coursera course costs about $\$ 7,000$ (USD) to produce; the cost absorbed by the university/college. The typical course involves 100 hours of taping, and the average number of hours per week devoted by faculty to the forum discussions is $8-10$ (stats from Wikipedia and Coursera). How about just saying, "thank you, professors, for this free opportunity to learn something new from one of the most prestigious institutions of learning on our planet," hmm?
}

This particular post received 14 positive votes. As with the Disneyland quote, it expressed a common sentiment observed across Coursera, edX, and Udacity discussion forums: that users who chose to say negative things about MOOCs were, to the pro-MOOC community, no more than "ungrateful complainers" with little respect for an educational resource provided by world-class institutions, online, and in most cases, for free. As one participant on Coursera's PatternOriented Software Architectures put it: "The instructors are just golden resources that only very few lucky ones have access to. Devaluing such treasures is an insult to everyone involved, including your fellow students." With regular expressions of such strong-held beliefs in the altruism and grandeur of MOOC instructors, so-called complainers were more than likely to attract negative votes for their posts, whereas those who expressed praise or support for MOOC endeavors were likely to receive positive votes.

Those coming to the defense of MOOCs were also quick to point out that participation in all courses was voluntary and that those who felt the need to criticize courses were ableand encouraged - to leave at any time. Some users took on a very aggressive tone in how they raised this fact, with one Udacity participant asserting a desire to "smash these whiners in the face." Another Udacity user claimed an urge to vote critical posts "down 10,000 times" if it meant such comments could be deleted by moderators for being deemed inappropriate in the eyes of course peers. Regardless of the particular tone taken in response, so-called attacks on MOOCs and their instructors indicated that not only were MOOCs not suited for everyone, but not everyone was welcome to join the MOOC community either. Post-voting simply worked to impose and bolster these messages.

\section{Discussion}

What these observations of interaction within MOOC discussion forums suggest is that post-voting-particularly in Coursera-has a distinct ritual function in MOOC forums. Indeed, post-voting has been shown to be a patterned and highly symbolic act, regularly repeated by users over time, with a common understanding of its purpose to communicate a message of agreement or disproval to others. By functioning in this manner, post-voting has worked to establish and reinforce social boundaries of good/right or bad/wrong, of belonging and marginalization. The simple but meaningful act of clicking a button to rate user posts has become a routine and visual display of allegiance or defiance toward the comments of others. Post-voting could therefore be deemed a coded performance of community membership, one which people either wish to obtain and retain, or from which they are effectively denied (Macfadyen, 2009).

It is precisely because MOOCs have been so "massive" and so "open"-and by extension, their user base so heterogeneousthat post-voting has taken on this ritual function; it has served as a shorthand way of communicating to the crowd. Such symbolic gestures, as Turner and Killian (1957, p. 120) suggest, are an inherent characteristic of crowds. As Durkheim (1961, p. 262) further contends, these kinds of symbolic gestures are what actually allow collective mentality, and ideas about expected behaviors, to become known to both insiders and outsiders. Indeed, the negotiation and maintenance of this social boundary 
are fundamental to the establishment and reinforcement of a sense of solidarity or community in any social group, crowd or otherwise (Gamson, 1997; Ghose, Swendeman, George, \& Chowdhury, 2008; Guenther, Mulligan, \& Papp, 2013; Melucci, 1996, pp. 73-74; Taylor \& Whittier, 1992). As Turner and Killian (1957, p. 253) note, feelings of social allegiance help reinforce collective mentality:

To the extent to which a person identifies himself strongly with any group, he feels ill at ease when his opinions are not those of the group. To the degree to which he feels that the members of a group are "his kind of people," he will be inclined to bring to the fore those attitudes within himself which will permit him to hold the group opinion as his own.

The notion that aligning one's views to those of the broader collective could enhance feelings of community provides further context to the issue of why the ritual of post-voting would be so widespread among MOOC users, given that it is by no means a mandated activity in terms of course participation. Only the number and direction of votes are counted, not the voters' identity. As such, post-voting seems to be just as much an "identity-affirming behavior"-of establishing where one sees themselves and places their allegiance, in relation to others-as it is a signal of approval or disproval (Simon, Trötschel, \& Dähne, 2008, p. 94).

As highlighted previously, the ritual of post-voting can also influence how users perceive MOOCs more broadly. Users who feel their posts are being "targeted" by negative voteswhatever the precise intention of the vote-giver-are likely to feel alienated from others and disconnected from peers. In other words, these "hounded" users are unlikely to perceive the MOOC environment as one constituting a supportive learning community. They are instead prone to view the experience of participating in a MOOC as an isolating one, whether or not that is what they intended or desired. In contrast, those whose posts are embraced by others are more likely to see MOOCs and their associated forums as welcoming spaces where the sense of community among users is strong. These differences in perception and experience suggest that post-voting can be classified into two categories: those which Guibernau (2013) defines as rituals of exclusion, which "seek to identify and punish traitors, to condemn unruly behavior within the group and to stigmatize aliens and enemies" and, on the flipside, rituals of inclusion, which "emphasize the 'expected' qualities of group members... enhance the power and superiority of the group and offer a clear idea of internal hierarchy" (p. 105). Considered in tandem, these two types of ritual communicate the normative standards required of those who wish to be part of the MOOC community, regarded here as the vocal "pro-MOOC" users. They articulate the social boundaries for what is "a little patch of commitment and loyalty with its own heroes and villains" (Goffman, 1967, pp. 113-114).

Denunciations of the villains-that is, those who provide critical views of MOOCs or their creators-indicate yet another important role that the ritual of post-voting has played in promoting community values. Such rebukes on "poor" values or behaviors reinforce the notion that MOOCs are above all, a social good, and that any complaints from dissatisfied users are not just indicative of ingratitude, they are just wrong. Guibernau (2013, p. 145) provides an apt description of this "blind faith" mentality:

Those who belong to a group tend to emphasize its positive qualities while excluding negative information and experiences capable of distorting an optimistic image.... This tendency to understand, explain and justify the deeds of fellow-members stands in stark contrast with a harsher attitude displayed when judging the deeds of "outsiders."

Knottnerus (2010, p. 49) argues in line with this premise of optimistic defense, proposing that prolonged engagement in a ritualized activity-like post-voting-increases the likelihood that participants in the ritual will perceive consensus among one another. In essence, the more users assign a positive or negative value to the comments of others, the more they will come to see that there are people who are like them and share their views. Though a feature imposed by the MOOC providers, post-voting could therefore be regarded as having been co-opted by MOOC users as a ritual for "indigenous policing" (Cohen, 1996, p. 376). It has become the means by which users negotiate boundaries around acceptable conduct or views, of how they celebrate certain values and behaviors and sanction others (Pankoke-Babatz \& Jeffrey, 2002). In effect, post-voting has become the site for the "fight for 'true' membership status" in the MOOC community (Gamson, 1997, p. 192).

As previously noted, Coursera's post-voting system appears to have the most profound symbolic quality in this regard. On the surface, the use of colored arrows, with positive and negative numerical values attributed to them, might seem like a small gesture in a larger interactive scheme. But, as this study has shown, it is precisely because these little up and down votes are so "small" yet wield such influence in changing the entire nature of social relations that they require further illumination. Indeed, as Magolda (2000, p. 37) suggests, it is the "little rituals" that can have the most profound effect on understanding the symbolic complexities in any form of social relation, none more so than in the construction and maintenance of online communities.

By incorporating post-voting mechanisms in their discussion forums, MOOC providers-particularly Coursera-have effectively, though perhaps not intentionally, embedded ritual into the interaction between users. On the one hand, by enabling the creation and maintenance of in-group/out-group boundaries, post-voting has worked to strengthen the prospect of community among the in-group as something distinct from the rest. On the other hand, post-voting has diminished the opportunity for social bonding for the group at large by alienating the minority of critical voices (the out-group). With respect to the latter, the ritual of post-voting has done little to support the development of a welcoming community among the broader MOOC populace; it has not promoted the idea of inclusivity on which MOOCs have been marketed. In essence, post-voting has worked against comprehensive membership in a community beyond simple enrolment in courses; it has promoted a degree of exclusivity among only those deemed "worthy" of such membership. 


\section{Conclusion}

The generation and preservation of community are an elusive objective invariably pursued by designers of online education platforms, including the most prominent Massive Open Online Course providers, Coursera, edX, and Udacity. As in the physical world, rituals that communicate social boundaries and expected behaviors can influence the creation of community in the online world. With MOOCs as a case study, this article has shown that, by incorporating a postvoting mechanism into each of their online discussion forum interfaces, MOOC providers-and Coursera in particularhave both enforced and undermined the development of community among users because of the ritual power such mechanisms have assumed. Rather than simply acting as a way for users to navigate through only the most popular and interesting forum posts, post-voting has become a means for users to defend MOOCs against their critics and silence minority voices. This ultimately has the effect of welcoming certain views, and by association, the posters communicating these views, in the (pro-) MOOC community while actively alienating others. Such is the influence that post-voting has on the nature of interaction in discussion forums that MOOC providers may wish to reflect on its use, and the potentially detrimental impact it can have on the mantra of inclusivity on which MOOCs have been founded. The same goes for any designers of online spaces intending to incroporate discussion forums as a way to establish a community among their users, education-based or otherwise: use post-voting wisely, as it can both enhance and undermine broader objectives for social bonding.

\section{Note}

1. Coursera and edX specifically stipulated that content generated by users was considered public information for use by others provided that there was no commercial gain and no deliberate attempts to harm or threaten users or the operations of the sites through hacking or other deliberate acts (Coursera, 2014b; edX, 2013). For Udacity, content was public but had to be paraphrased as, unlike Coursera and edX, it stated that users were "the sole and exclusive owner of any and all rights, title and interest in and to the User Content" (Udacity, 2013).

\section{References}

Bagozzi, R., \& Dholakia, U. (2002). Intentional social action in virtual communities. Journal of Interactive Marketing, 16(2), 2-21.

Bell, C. (2009). Ritual theory, ritual practice. New York, NY: Oxford University Press.

Bennett, R., Chan, L. K., \& Polaine, A. (2004, September). The future has already happened: Dispelling some myths of online education. Paper presented at the Australian Council of University Art and Design Schools Annual Conference, Canberra.

Bowker, N., \& Tuffin, K. (2004). Using the online medium for discursive research about people with disabilities. Social Science Computer Review, 22(2), 228-241.

Boyd, J. (2002). In community we trust: Online security communication at eBay. Journal of Computer-Mediated Communication, 7(3). doi:10.1111/j.1083-6101.2002.tb00147

Brotsky, S. R., \& Giles, D. (2007). Inside the 'Pro-ana' community: A covert online participant observation. Eating Disorders: The Journal of Treatment and Prevention, 15(2), 93-109.
Cohen, C. J. (1996). Contested membership: Black gay identities and the politics of AIDS. In S. Seidman (Ed.), Queer theory sociology (pp. 362-394). Cambridge, MA: Blackwell.

Collins, R. (2004). Interaction ritual chains. Princeton, NJ: Princeton University Press.

Connerton, P. (1989). How societies remember. Cambridge, UK: Cambridge University Press.

Conrad, D. (2002). Deep in the hearts of learners: Insights into the nature of online community. International Journal of E-Learning \& Distance Education, 17(1), 1-19.

Coursera. (2014a, February 23). About us. Coursera.org. Retrieved March 18, 2014, from https://www.coursera.org/about

Coursera. (2014b, January 2). Terms of Use. Coursera.org. Retrieved June 3, 2014, from https://www.coursera.org/about/terms

Dawson, S. (2006). Online forum discussion interactions as an indicator of student community. Australasian Journal of Educational Technology, 22(4), 495-510.

deNoyelles, A., Zydney, J., \& Chen, B. (2014). Strategies for creating a community of inquiry through online asynchronous discussions. Journal of Online Learning and Teaching, 10(1), 153-165.

Durkheim, E. (1961). The elementary forms of the religious life (J. W. Swain, Trans.). New York, NY: Collier Books.

edX. (2013, September 17). Terms of service. edX.org. Retrieved June 3, 2014, from https://www.edx.org/edx-terms-service

edX. (2014a, March 14). About us. edX.org. Retrieved March 18, 2014, from https://www.edx.org/about-us

edX. (2014b, March 17). How it works. edX.org. Retrieved March 18, 2014, from https://www.edx.org/how-it-works

Elm, M. S. (2009). How do various notions of privacy influence decisions in qualitative internet research? In A. N. Markham \& N. K. Baym (Eds.), Internet inquiry: Conversations about method (pp. 69-87). Thousand Oaks, CA: SAGE.

Eysenbach, G., \& Till, J. E. (2001). Ethical issues in qualitative research on Internet communities. British Medical Journal, 323(7321), $1103-1105$.

Fernback, J. (2007). Beyond the diluted community concept: A symbolic interactionist perspective on online social relations. New Media \& Society, 9(1), 49-69.

Gamson, J. (1997). Messages of exclusion: Gender, movements, and symbolic boundaries. Gender \& Society, 11(2), 178-199.

Garton, L., Haythornthwaite, C., \& Wellman, B. (1997). Studying online social networks. Journal of Computer-Mediated Communication, 3(1). doi:10.1111/j.1083-6101.1997.tb00062.x

Ghose, T., Swendeman, D., George, S., \& Chowdhury, D. (2008). Mobilizing collective identity to reduce HIV risk among sex workers in Sonagachi, India: The boundaries, consciousness, negotiation framework. Social Science \& Medicine, 67(2), 311-320.

Goffman, E. (1967). Interaction ritual. New York, NY: Pantheon Books.

Guenther, K. M., Mulligan, K., \& Papp, C. (2013). From the outside in: Crossing boundaries to build collective identity in the new atheist movement. Social Problems, 60(4), 457-475.

Guibernau, M. (2013). Belonging: solidarity and division in modern societies. Cambridge, UK: Polity Press.

Guilar, J. D., \& Loring, A. (2008). Dialogue and community in online learning: Lessons from Royal Roads University. Journal of Distance Education, 22(3), 19-40.

Hillery, G. A. (1968). Communal organizations: A study of local societies. Chicago, IL \& London, UK: University of Chicago Press.

Hine, C. (2009). How can qualitative internet researchers define the boundaries of their projects? In A. N. Markham \& N. K. Baym (Eds.), Internet inquiry: Conversations about method (pp. 1-20). Thousand Oaks, CA: SAGE.

Hobsbawm, E. J. (1959). Primitive rebels. Manchester, UK: Manchester University Press.

Horchler, J. (2001). Building learning communities in cyberspace. American Secondary Education, 29(4). Retrieved from http://search proquest.com/docview/195184926?accountid $=8330$

Hudson, J. M., \& Bruckman, A. (2004). 'Go Away': Participant objections to being studied and the ethics of chatroom research. The Information Society: An International Journal, 20(2), 127-139. 
Huff, C. W., \& Rosenberg, J. (1989). The online voyeur: Promises and pitfalls of observing electronic interaction. Behavior Research Methods, Instruments, \& Computers, 21(2), 166-172.

Jackson, P. (1983). Principles and problems of participant observation. Geografiska Annaler. Series B, Human Geography, 65(1), 39-46.

Joanne, M. M., \& Tim, S. R. (2004). Online learning: Social interaction and the creation of a sense of community. Journal of Educational Technology \& Society, 7(3), 73-81.

Kawulich, B. B. (2005). Participant observation as a data collection method. Forum: Qualitative Social Research, 6(2). Retrieved from http://www. qualitative-research.net/index.php/fqs/article/view/466/996

Kellar, M., Hawkey, K., Inkpen, K. M., \& Watters, C. (2008). Challenges of capturing natural web-based user behaviors. International Journal of Human-Computer Interaction, 24(4), 385-409.

Knottnerus, J. D. (2010). Collective events, rituals, and emotions. Advances in Group Processes, 27, 39-61.

Kozinets, R. V. (2002). The field behind the screen: Using netnography for marketing research in online communities. Journal of Marketing Research, 39(1), 61-72.

Lareau, A. (2011). Unequal childhoods: Class, race, and family life (2nd ed.). Berkeley, CA: University of California Press.

Lee, J., \& Lee, H. (2010). The computer-mediated communication network: Exploring the linkage between the online community and social capital. New Media \& Society, 12(5), 1-17.

Lin, C.-P. (2010). Learning virtual community loyalty behavior from a perspective of social cognitive theory. International Journal of Human-Computer Interaction, 26(4), 345-360.

Macfadyen, L. P. (2009). Being and learning in the online classroom: Linguistic practices and ritual text acts. In R. Goodfellow \& M.-N. Lamy (Eds.), Learning cultures in online education (pp. 93-112). London, UK: Continum.

Magolda, P. M. (2000). The campus tour: Ritual and community in higher education. Anthropology \& Education Quarterly, 31(1), 24-46.

Maloney, P. (2013). Online networks and emotional energy. Information, Communication \& Society, 16(1), 105-124.

Melucci, A. (1996). Challenging codes: Collective action in the information age. Cambridge, UK: Cambridge University Press.

Milan, S. (2015). From social movements to cloud protesting: The evolution of collective identity. Information, Communication \& Society, 18 (8), 887-900.

Orgad, S. (2009). How can researchers make sense of the issues involved in collecting and interpreting online and offline data? In A. N. Markham \& N. K. Baym (Eds.), Internet inquiry: Conversations about method (pp. 33-53). Thousand Oaks, CA: SAGE.

Palloff, R. M., \& Pratt, K. (2005). Collaborating online: Learning together in community. San Francisco, CA: Jossey-Bass.

Pankoke-Babatz, U., \& Jeffrey, P. (2002). Documented norms and conventions on the Internet. International Journal of Human-Computer Interaction, 14(2), 219-235.

Parr, J., \& Ward, L. (2006). Building on foundations: Creating an online community. Journal of Technology and Teacher Education, 14(4), 775-793.

Phirangee, K., Demmans Epp, C., \& Hewitt, J. (2016). Exploring the relationships between facilitation methods, students' sense of community, and their online behaviors. Online Learning Journal, 20(2), 134-154.

Rawls, A. (2004). Epistemology and practice: Durkheim's "The Elementary Forms of the Religious Life". Cambridge, UK: Cambridge University Press.

Rook, D. W. (1985). The ritual dimension of consumer behavior. Journal of Consumer Research, 12(3), 251-264.

Schwartz, M. S., \& Schwartz, C. G. (1955). Problems in participant observation. American Journal of Sociology, 60(4), 343-353.

Shackelford, J. L., \& Maxwell, M. (2012). Sense of community in graduate online education: Contribution of learner to learner interaction. The International Review of Research in Open and Distributed Learning, 13(4), 228-249.

Simon, B., Trötschel, R., \& Dähne, D. (2008). Identity affirmation and social movement support. European Journal of Social Psychology, 38(6), 935-946.

Smith, C. B. (2006). Casting the net: Surveying an Internet population. Journal of Computer-Mediated Communication, 3(1). doi:10.1111/ j.1083-6101.1997.tb00064.x

Sutcliffe, A. G., Gonzalez, V., Binder, J., \& Nevarez, G. (2011). Social mediating technologies: Social affordances and functionalities. International Journal of Human-Computer Interaction, 27(11), 1037-1065.

Tambiah, S. J. (1979). Performative approach to ritual. Proceedings of the British Academy (65, pp. 113-169).

Taylor, V., \& Whittier, N. (1992). Collective identity in social movement communities: Lesbian feminist moblization. In A. D. Morris \& C. M. Mueller (Eds.), Frontiers in social movement theory (pp. 104-129). New Haven, CT: Yale University Press.

Taylor, V., \& Whittier, N. (1995). Analytical approaches to social movement culture: The culture of the women's movement. In H. Johnston \& B. Klandermans (Eds.), Social movements and culture (pp. 163-187). Minneapolis, MN: University of Minnesota Press.

Tinto, V. (1993). Leaving college: Rethinking the causes and cures of student attrition (2nd ed.). Chicago, IL: University of Chicago Press.

Toder-Alon, A., Brunel, F. F., \& Schneier Siegal, W. L. (2005). Ritual behavior and community change: Exploring the social psychological roles of net rituals in the developmental processes of online consumption communities. In C. P. Haugtvedt, K. A. Machleit, \& R. Yalch (Eds.), Online consumer psychology: Understanding and influencing consumer behavior in the virtual world (pp. 7-35). Mahwah, NJ: Lawrence Erlbaum Associates, Inc.

Turner, R. H., \& Killian, L. M. (1957). Collective behavior. Englewood Cliffs, NJ: Prentice Hall.

Turner, V. (1974). Dramas, fields, and metaphors: Symbolic action in human society. Ithaca, NY: Cornell University Press.

Udacity. (2013, November 14). Terms of service. Udacity.com. Retrieved June 3, 2014, from https://www.udacity.com/legal/tos

Udacity. (2014a, March 13). About us. Udacity.com. Retrieved March 18, 2014, from https://www.udacity.com/us

Udacity. (2014b, April 11). What we offer. Udacity.com. Retrieved April 18, 2014, from https://www.udacity.com/what-we-offer

Waskul, D., \& Douglass, M. (1996). Considering the electronic participant: Some polemical observations on the ethics of online research. The Information Society: An International Journal, 12(2), 129-140.

Wilson, B. G., Ludwig-Hardman, S., Thornam, C. L., \& Dunlap, J. C. (2004). Bounded community: Designing and facilitating learning communities in formal courses. International Review of Research in Open and Distance Learning, 5(3). Retrieved from http://www.irrodl.org/ index.php/irrodl/article/view/204/286

Wuthnow, R. (1987). Meaning and moral order. Berkeley, CA: University of California Press.

Xu, B., Li, D., \& Shao, B. (2012). Knowledge sharing in virtual communities: A study of citizenship behavior and its social-relational antecedents. International Journal of Human-Computer Interaction, 28(5), 347-359.

\section{About the Author}

Emily Longstaff is a Sociology $\mathrm{PhD}$ candidate at the Australian National University (ANU). She has a Bachelor of Arts with First Class Honors in Sociology, also from ANU, as well as a Master of Cross-disciplinary Art and Design from the University of New South Wales. 